\title{
Computed tomography-guided percutaneous biopsy of pancreatic masses using pneumodissection*
}

\author{
Biópsia percutânea de massas pancreáticas guiada por tomografia computadorizada com pneumodissecção \\ Chiang Jeng Tyng ${ }^{1}$, Almir Galvão Vieira Bitencourt ${ }^{2}$, Maria Fernanda Arruda Almeida ${ }^{3}$, Paula Nicole \\ Vieira Barbosa ${ }^{1}$, Eduardo Bruno Lobato Martins ${ }^{2}$, João Paulo Kawaoka Matushita Junior ${ }^{4}$, Rubens \\ Chojniak $^{5}$, Felipe José Fernandez Coimbra ${ }^{6}$
}

\begin{abstract}
Objective: To describe the technique of computed tomography-guided percutaneous biopsy of pancreatic tumors with pneumodissection. Materials and Methods: In the period from June 2011 to May 2012, seven computed tomographyguided percutaneous biopsies of pancreatic tumors utilizing pneumodissection were performed in the authors' institution. All the procedures were performed with an automatic biopsy gun and coaxial system with Tru-core needles. The biopsy specimens were histologically assessed. Results: In all the cases the pancreatic mass could not be directly approached by computed tomography without passing through major organs and structures. The injection of air allowed the displacement of adjacent structures and creation of a safe coaxial needle pathway toward the lesion. Biopsy was successfully performed in all the cases, yielding appropriate specimens for pathological analysis. Conclusion: Pneumodissection is a safe, inexpensive and technically easy approach to perform percutaneous biopsy in selected cases where direct access to the pancreatic tumor is not feasible.
\end{abstract}

Keywords: Pancreatic neoplasms; Needle biopsy; Computed tomography.

Resumo Objetivo: Descrever a técnica de biópsia percutânea de tumores pancreáticos guiada por tomografia computadorizada com pneumodissecção. Materiais e Métodos: No período de junho de 2011 a maio de 2012, foram realizadas sete biópsias percutâneas de tumores pancreáticos guiadas por tomografia computadorizada utilizando a manobra de pneumodissecção em nossa instituição. Todas as biópsias foram realizadas utilizando pistola de disparo automático e sistema coaxial, com agulhas Tru-core. As amostras colhidas foram submetidas a avaliação histológica. Resultados: Para todos os casos, não havia um acesso direto seguro pela tomografia computadorizada para atingir o tumor pancreático sem atravessar órgãos e estruturas importantes. A injeção de ar foi capaz de deslocar as estruturas adjacentes e criar uma nova rota de acesso, permitindo um trajeto seguro da agulha coaxial até a lesão, e a biópsia foi realizada com sucesso em todos os casos. Todas as biópsias forneceram material suficiente para análise histológica. Conclusão: Esta técnica é segura, barata e tecnicamente fácil, podendo auxiliar na realização de biópsias percutâneas de tumores pancreáticos guiadas por tomografia computadorizada de casos selecionados em que não existe acesso direto à lesão.

Unitermos: Neoplasias pancreáticas; Biópsia por agulha; Tomografia computadorizada.

Tyng CJ, Bitencourt AGV, Almeida MFA, Barbosa PNV, Martins EBL, Matushita Junior JPK, Chojniak R, Coimbra FJF. Computed tomographyguided percutaneous biopsy of pancreatic masses using pneumodissection. Radiol Bras. 2013 Mai/Jun;46(3):139-142.

\section{INTRODUCTION}

Focal pancreatic lesions may be related to several pathological conditions, with different therapeutic options. With the ad-

* Study developed at Hospital A. C. Camargo, São Paulo, SP, Brazil.

1. Masters and Fellows PhD degree, Full Professors, Department of Imaging, Hospital A. C. Camargo, São Paulo, SP, Brazil.

2. PhDs, Full Professors, Department of Imaging, Hospita A. C. Camargo, São Paulo, SP, Brazil.

3. Fellow PhD degree, Department of Imaging, Hospital A. C. Camargo, São Paulo, SP, Brazil.

4. Master, Department of Imaging, Hospital A. C. Camargo, São Paulo, SP, Brazil.

5. PhD, Director, Department of Imaging, Hospital A. C. Camargo, São Paulo, SP, Brazil.

6. PhD, Director, Department of Abdominal Surgery, Hospital A. C. Camargo, São Paulo, SP, Brazil. vances of imaging methods, including functional evaluation by positron emission computed tomography and by magnetic resonance imaging ${ }^{(\mathbf{1})}$, the diagnosis can be suggested with no need for invasive procedures. In some cases, the non-invasive imaging evaluation cannot establish an accurate diagnosis, and a histological analysis is required before the treatment. There are several techniques of collection of specimens for histological analysis of pancreatic

Mailing Address: Dr. Chiang Jeng Tyng. Rua Professor Antônio Prudente, 211, Liberdade. São Paulo, SP, Brazil, 01509 010. E-mail: chiangjengtyng@gmail.com.

Received November 11, 2012. Accepted after revision February $7,2013$. lesions such as imaging-guided percutaneous biopsy, and endoscopic or surgical biopsies $^{(2)}$.

Recently, a series of studies published in Brazil have highlighted the relevance of interventional radiology in the diagnosis and treatment of diseases in different compartments of the body ${ }^{(3-10)}$. Computed tomography (CT)-guided percutaneous biopsy is a safe and well-established technique, with high accuracy in the diagnosis of focal pancreatic lesions and low rate of complications $^{(\mathbf{1 1}, \mathbf{1 2})}$.

Most pancreatic biopsies involve direct approach to the organ. However, different overlying anatomic structures, such as the 
stomach, bowel loops, liver, kidneys, spleen and vessels may preclude a safe and direct access to the lesion. In such cases, alternative techniques can be utilized to access the lesion.

The present article is aimed at describing the technique of CT-guided percutaneous biopsy of pancreatic tumors with pneumodissection.

\section{MATERIALS AND METHODS}

In the period from June 2011 to May 2012, seven CT-guided percutaneous biopsies of pancreatic tumors utilizing pneumodissection were undertaken in the authors' institution. All the procedures were performed with an automatic biopsy gun and coaxial system with Tru-core needles (Angiotech; Vancouver, Canada) measuring $10 \mathrm{~cm}$ or $15 \mathrm{~cm}$, depending on the distance between the skin and the lesion. Coagulation tests were performed as a preprocedural routine. The collected specimens were submitted to histological analysis.

\section{Biopsy technique}

The preferential position for biopsy is that most comfortable for the patient, which most frequently is the prone position. After asepsis and local anesthesia with lidocaine $2 \%$, a 17 -gauge coaxial needle is inserted into the intra-abdominal fatty tissue and new CT images are acquired for access route planning. After correction of the needle tip location, 50 to $100 \mathrm{ml}$ of air are injected to displace the adjacent organs and structures, while the needle is carefully advanced through the newly created access route under CT guidance. Once the coaxial needle is positioned inside or adjacent to the organ, five or six specimens are obtained with an 18-gauge cutting needle. The number of specimens may be higher or lower, depending on the quality of such specimens and on the presence of bleeding or other complications. The whole procedure takes about 30 minutes to be completed.

\section{RESULTS}

In this study, most patients were women and the mean age was 69 years, ranging between 39 and 82 years. In five cases, the lesion was located in the pancreatic head, and in two cases, in the body or tail of the pancreas. The mean diameter of the lesions was $33 \mathrm{~mm}$, ranging between 17 and 47 $\mathrm{mm}$. Table 1 describes all patients' data.

In all the cases the pancreatic tumor could not be safely approached by CT without passing through major organs and structures. The patients were positioned in lateral/oblique (Figure 1), dorsal or ventral decubitus (Figure 2), depending on the location of the lesion and on the planned biopsy route. The air injection could displace adjacent structures, creating a new access route to allow a safe advance of the coaxial needle up to the lesion. Biopsy could be successfully performed in all the cases.

No significant bleeding was observed during the procedure and none of the patients complained of important pain during the air injection. One patient presented subtle pneumothorax during the procedure, but drainage was not required. Another patient present slight increase in serum levels of pancreatic enzymes, which resolved spontaneously with no specific treatment. No late complication was reported.

All biopsies provided sufficient material for histological analysis. Five lesions were confirmed as primary pancreatic adenocarcinoma, and two patients presented metastatic lesions (one from melanoma and other from epidermoid carcinoma of the scalp).

\section{DISCUSSION}

Several techniques have been described for percutaneous biopsy of pancreatic tumors where direct access to the lesion is not feasible, with good results and low rates of complications $^{(\mathbf{1 2})}$. Such techniques include transgastric and transhepatic biopsies and hydrodissection maneuvers. Hydrodissections maneuver may also be utilized to displace structures such as vessels and bowel loops, creating a safe access route for biopsy. Such a technique has already been described for other locations such as adrenal and mediastinal lesions ${ }^{(\mathbf{1 3 , 1 4})}$.

Pneumodissection may be utilized either isolatedly or in association with hydrodissection to displace nontarget structures. However, few authors have described the utilization of such maneuver in percutaneous procedures. In pneumodissection, either ambient air or carbon dioxide $\left(\mathrm{CO}_{2}\right)$ may be injected with a syringe capable of delivering controlled gas volumes to the area of interest. A relatively great amount of gas may be injected in a way that, even in case the needle cannot be positioned between the lesion and the adjacent organs, such organs can be separated, provided a sufficient amount of gas is injected into the compartment. Both liquids and gas tend to disperse as they are injected into the abdominal cavity. Liquids tend to accumulate in the lower regions, while gas tends to accumulate in the superior regions, which may be useful in the selection of the material to be utilized to displace the nontarget structures in each specific case.

The safety of the intra-abdominal $\mathrm{CO}_{2}$ injection has already been proved in studies about laparoscopy. $\mathrm{CO}_{2}$ pulmonary embolism has already described during laparoscopic surgery ${ }^{(\mathbf{1 5})}$. However, the amount of $\mathrm{CO}_{2}$ utilized during laparoscopy is much greater than the amount utilized in percutaneous procedures. Kariya et al. ${ }^{(\mathbf{1 6})}$ and Buy et al. ${ }^{(17)}$ have described cases of pneumodissection with $\mathrm{CO}_{2}$ in percutaneous radioablation of abdominal tumors, utilizing up to $1,500 \mathrm{ml}$ of gas, without complications. The probability of pulmonary embolism seems to be minimal with the amount of gas utilized in the presently reported procedures.

Table 1 Data from seven patients submitted to CT-guided percutaneous biopsy of pancreatic lesions with pneumodissection maneuver.

\begin{tabular}{ccccc}
\hline Sex / age & Location & Size $(\mathrm{mm})$ & Biopsy access & Histological result \\
\hline F / 54 years & Pancreatic head & 40 & Posterior (left) & Adenocarcinoma \\
F / 75 years & Pancreatic head & 17 & Posterior (right) & Adenocarcinoma \\
F / 39 years & Pancreatic head & 44 & Posterior (right) & Adenocarcinoma \\
F / 52 years & Pancreatic head & 20 & Anterior & Metastatic SCC \\
F / 52 years & Pancreatic head & 25 & Posterior (right) & Metastatic melanoma \\
F / 51 years & Pancreatic body & 47 & Lateral (left) & Adenocarcinoma \\
M / 82 years & Pancreatic tail & 40 & Lateral (left) & Adenocarcinoma \\
\hline
\end{tabular}

F, female; M, male; SCC, squamous cell or epidermoid carcinoma. 
Figure 1. Male, 82-year-old patient submitted to CT-guided percutaneous biopsy of a pancreatic mass, with lateral approach and pneumodissection maneuver. A: Contrast-enhanced, axial CT section demonstrates an ill-defined lesion in the pancreatic tail (star). B: Preprocedural planning CT image acquired with the patient positioned in lateral decubitus demonstrates the left kidney, spleen and stomach overlying between the lesion and the abdominal wall. C: Air was injected into the perirenal space, widening the gap between the left kidney and the spleen. D: CT image demonstrates the progression of the coaxial needle through the space created by pneumodissection and the needle positioning adjacent to the lesion. The histological result corresponded to adenocarcinoma.

Figure 2. Female, 52-year-old patient submitted to CT-guided percutaneous biopsy of pancreatic tumor, with posterior approach and pneumodissection maneuver. A: Contrastenhanced, axial CT section shows hypodense lesion in the pancreatic head (star). B: Computed tomography image acquired with the patient in ventral decubitus demonstrates the needle positioned in the right paravertebral space. C: Air was injected into the paravertebral space, widening the gap between the right kidney and the inferior vena cava (arrow). D: CT image demonstrates the positioning of the coaxial needle between the right kidney and the inferior vena cava, adjacent to the pancreatic lesion. The histological result corresponded to metastatic melanoma.
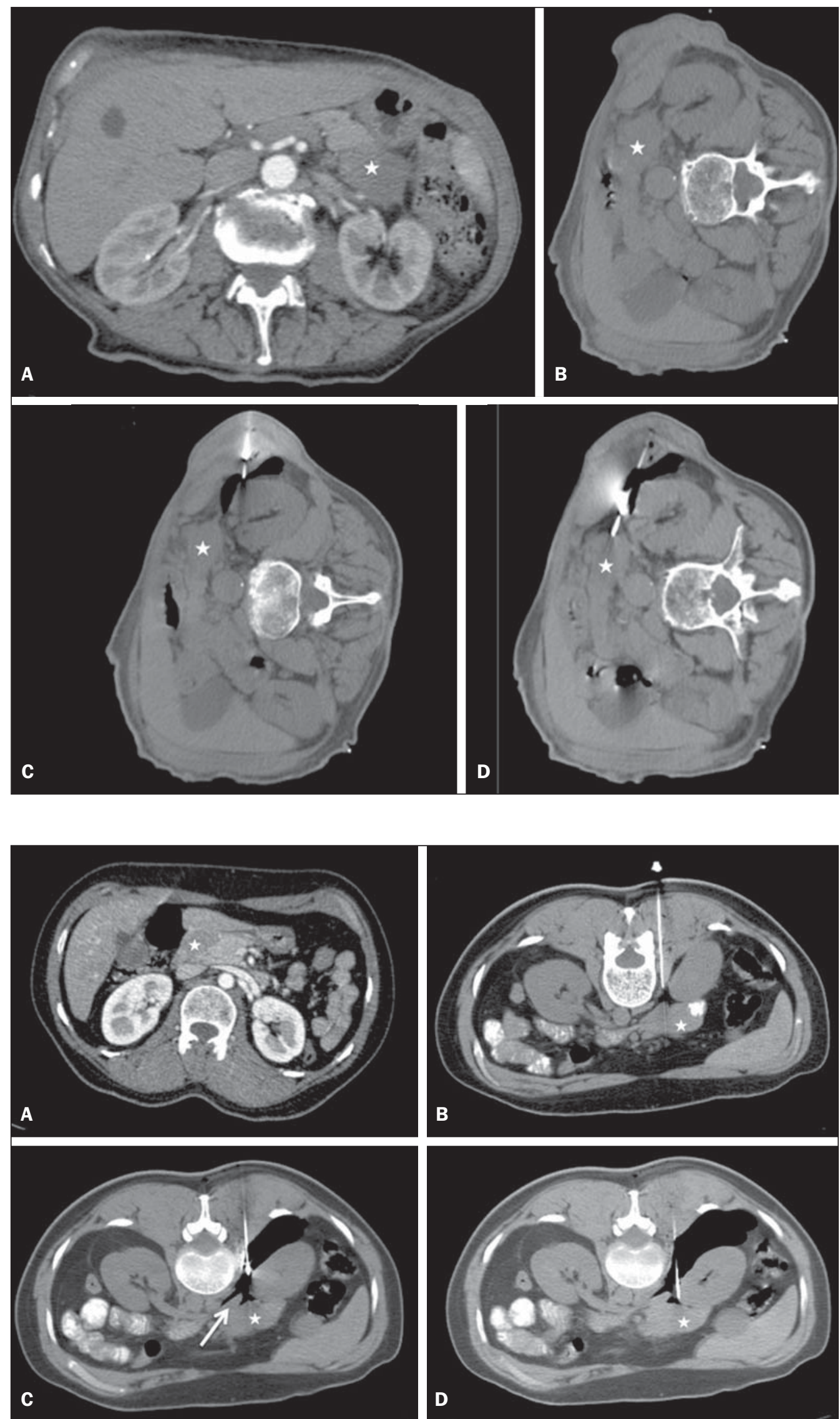
In the presently described cases, the pancreatic tumors were involved by other abdominal organs or structures such as bowel loops, kidneys, liver, spleen and great vessels. The approach through the liver, spleen or kidneys should be avoided because of the risk for bleeding. Fine needle puncture through the gastrointestinal tract seems to be safe, however no study about core biopsy is found in the literature, so the possibility of peritonitis should ever been considered. Thus, the pneumodissection maneuver was selected as the best approach for these specific lesions, avoiding the involvement of adjacent organs and reducing the risks inherent to the procedure.

Finally, pneumodissection is a safe, low-cost and technically easy-to-perform maneuver that may be useful in selected cases requiring $\mathrm{CT}$-guided percutaneous biopsy of pancreatic tumors where direct access to the lesion is not feasible.

\section{REFERENCES}

1. Hernandes MA, Semelka RC, Elias Jr J, et al. Whole-body MRI: comprehensive evaluation on a 48-channel 3T MRI system in less than 40 min- utes. Preliminary results. Radiol Bras. 2012;45: 319-25.

2. Goldin SB, Bradner MW, Zervos EE, et al. Assessment of pancreatic neoplasms: review of biopsy techniques. J Gastrointest Surg. 2007;11:783-90

3. Chojniak R, Pinto PNV, Tyng CJ, et al. Computed tomography-guided transthoracic needle biopsy of pulmonary nodules. Radiol Bras. 2011;44:31520.

4. Chojniak R, Grigio HR, Bitencourt AGV, et al. Percutaneous computed tomography-guided core needle biopsy of soft tissue tumors: results and correlation with surgical specimen analysis. Radiol Bras. 2012;45:259-62.

5. Guimarães MD, Fonte AC, Andrade MQ, et al. Computed tomography-guided core-needle biopsy of lung lesions: an oncology center experience. Radiol Bras. 2011;44:75-80.

6. Wajnberg E, Rodrigues G, Abud DG. Use of drugeluting stents for the treatment of vertebral artery stenosis. Radiol Bras. 2011;44:343-8.

7. Queiroz HMC, Costa FA, Campos Jr MM, et al. Arterial embolization in the treatment of hemobilia after hepatic trauma: a case report. Radiol Bras. 2012;45:63-4.

8. Ceratti S, Giannini P, Souza RAS, et al. Ultrasound-guided fine-needle aspiration of thyroid nodules: assessment of the ideal number of punctures. Radiol Bras. 2012;45:145-8.

9. Novero ER, Metzger PB, Obregon J, et al. Endovascular treatment of thoracic aortic diseases: a single center result analysis. Radiol Bras. 2012; 45:251-8.
10. Ceratti S, Okano FM, Pontes ABG, et al. Ultrasound-guided foam sclerotherapy in the treatment of chronic venous insufficiency. Radiol Bras. 2011;44:167-71.

11. Paulsen SD, Nghiem HV, Negussie E, et al. Evaluation of imaging-guided core biopsy of pancreatic masses. AJR Am J Roentgenol. 2006;187:769_ 72 .

12. Tseng HS, Chen CY, Chan WP, et al. Percutaneous transgastric computed tomography-guided biopsy of the pancreas using large needles. World J Gastroenterol. 2009;15:5972-5.

13. Tyng CJ, Bitencourt AG, Martins EB, et al. Technical note: CT-guided paravertebral adrenal biopsy using hydrodissection - a safe and technically easy approach. Br J Radiol. 2012;85:e33942.

14. de Bazelaire C, Sabatier F, Pluvinage A, et al. CTguided percutaneous biopsies. J Radiol. 2011;92: 842-59.

15. Dion YM, Lévesque C, Doillon CJ. Experimental carbon dioxide pulmonary embolization after vena cava laceration under pneumoperitoneum. Surg Endosc. 1995;9:1065-9.

16. Kariya S, Tanigawa N, Kojima H, et al. Radiofrequency ablation combined with $\mathrm{CO} 2$ injection for treatment of retroperitoneal tumor: protecting surrounding organs against thermal injury. AJR Am J Roentgenol. 2005;185:890-3.

17. Buy X, Tok CH, Szwarc D, et al. Thermal protection during percutaneous thermal ablation procedures: interest of carbon dioxide dissection and temperature monitoring. Cardiovasc Intervent Radiol. 2009;32:529-34. 